\title{
Site-dependent decrease of odour-related peak-to-mean factors with distance
}

\author{
M. Piringer ${ }^{1}$, W. Knauder ${ }^{1}$, E. Petz ${ }^{1}$, and G. Schauberger ${ }^{2}$ \\ ${ }^{1}$ Central Institute for Meteorology and Geodynamics, Vienna, Austria \\ ${ }^{2}$ Unit for Physiology and Biophysics, University of Veterinary Medicine, Vienna, Austria \\ Correspondence to: M. Piringer (martin.piringer@zamg.ac.at)
}

Received: 10 January 2014 - Revised: 13 June 2014 - Accepted: 16 June 2014 - Published: 3 July 2014

\begin{abstract}
The peak-to-mean concept developed earlier by the authors to calculate odour-related separation distances is applied here to meteorological input for dispersion models provided by ultrasonic anemometers. In addition to conventional meteorological input parameters like wind direction, wind speed and stability classes, three-dimensional sonics provide also turbulence information via the Obukhov stability parameter and the variance of the wind speed, which can be used directly to determine peak-to-mean ratios depending on the distance from the source. The influence and importance of these site-specific peak-to-mean ratios on the resulting direction-dependent separation distances is investigated and discussed.
\end{abstract}

\section{Introduction}

Odour perception is a biological reaction of humans. The relevant time scale is the duration of a single human breath, i.e. $4 \mathrm{~s}$ on average (Kleemann et al., 2009). (Regulatory) dispersion models, which usually calculate half-hourly or hourly averages of concentrations, have to be adapted somehow to parameterize the relevant short-term odour concentrations. The peak-to-mean concept is a mean to parameterize short-term concentrations in dispersion models, used in several European countries and in Australian and US states (for an overview on regulations in different countries, see Piringer and Schauberger, 2013). Schauberger et al. (2012) discuss different definitions of the peak value and models (e.g. Best et al., 2001) of its reduction with distance.

For Austria, the authors developed a peak-to-mean approach depending on meteorological conditions used for the regulatory Austrian Gauss model; this algorithm is used in the Austrian Odour Dispersion Model (AODM) and described by Schauberger et al. (2000) and Piringer et al. (2007). In short, AODM consists of three modules: the first calculates the odour emission of a livestock building, taking also into account the diurnal variation caused by animal activity; the second estimates half-hourly or hourly ambient concentrations using a regulatory dispersion model, and the third transforms the mean odour concentrations of the dispersion model to instantaneous values depending on the stability of the near-surface layer. The regulatory model is a Gaussian plume model applied for single stack emissions and distances from $100 \mathrm{~m}$ to $15 \mathrm{~km}$. The model uses a traditional discrete stability classification scheme with dispersion parameters developed by Reuter (1970). It has been evaluated against a data set from the German environmental programme BWPLUS within the project "Odour emission and spread" (Baechlin et al., 2002); results are discussed in Piringer and Baumann-Stanzer (2009). In Piringer et al. (2007), the possibility to take the necessary meteorological information from three-dimensional (3-D) ultrasonic anemometers to arrive at site-specific attenuation curves for the peak-to-mean factor was already discussed. This approach is demonstrated herein for two Austrian sites with different meteorological conditions. The resulting directiondependent separation distances are compared to those obtained from the original attenuation curves.

\section{Method and sites}

In the next section, the results are presented for two Austrian sites, namely the city of Linz and the village of Kittsee at the border to Slovakia and Hungary. Both sites are characterized by flat grass-covered terrain without nearby obstacles. 
Table 1. Ratios of the standard deviations of the three wind components $\sigma_{u}, \sigma_{v}$ and $\sigma_{w}$ to the horizontal wind velocity $u$ depending on the stability of the atmosphere. Values proposed by Robins (1979) are compared to site-specific ratios derived from 3-D ultrasonic anemometer measurements (OSP).

\begin{tabular}{|c|c|c|c|c|c|c|c|}
\hline \multicolumn{2}{|c|}{ Stability class } & \multicolumn{2}{|c|}{$\sigma_{u} / u$} & \multicolumn{2}{|c|}{$\sigma_{v} / u$} & \multicolumn{2}{|c|}{$\sigma_{w} / u$} \\
\hline & & Robins & OSP & Robins & OSP & Robins & OSP \\
\hline \multicolumn{8}{|c|}{ (a) $\operatorname{Linz}$} \\
\hline 2 & very unstable & 0.2 & 0.53 & 0.2 & 0.53 & 0.3 & 0.27 \\
\hline 3 & unstable & 0.2 & 0.44 & 0.2 & 0.42 & 0.2 & 0.20 \\
\hline 4 & neutral & 0.2 & 0.37 & 0.2 & 0.31 & 0.1 & 0.17 \\
\hline 5 & slight stable & 0.2 & 0.43 & 0.2 & 0.38 & 0.1 & 0.18 \\
\hline 6 & stable & 0.2 & 0.46 & 0.2 & 0.43 & 0.1 & 0.18 \\
\hline 7 & very stable & 0.2 & 0.46 & 0.2 & 0.43 & 0.1 & 0.16 \\
\hline \multicolumn{8}{|c|}{ (b) Kittsee } \\
\hline 2 & very unstable & 0.2 & 0.40 & 0.2 & 0.39 & 0.3 & 0.19 \\
\hline 3 & unstable & 0.2 & 0.27 & 0.2 & 0.26 & 0.2 & 0.12 \\
\hline 4 & neutral & 0.2 & 0.19 & 0.2 & 0.17 & 0.1 & 0.08 \\
\hline 5 & slight stable & 0.2 & 0.19 & 0.2 & 0.15 & 0.1 & 0.08 \\
\hline 6 & stable & 0.2 & 0.20 & 0.2 & 0.17 & 0.1 & 0.08 \\
\hline 7 & very stable & 0.2 & 0.20 & 0.2 & 0.18 & 0.1 & 0.07 \\
\hline
\end{tabular}

The ultrasonic anemometer was mounted on top of a $10 \mathrm{~m}$ high mast at both sites. At Linz, a site characteristic of the Austrian North-Alpine foreland, we can expect a west-east orientation of the wind regime. Westerly airflow in Linz is frequently connected with cyclonic conditions. The easterly wind directions generally lead to fair-weather conditions but can also be indicative of the flow ahead of cyclones arriving from the West. Kittsee can experience high wind speeds, mainly from northwesterly directions often associated with frontal systems and storms. The secondary most frequent wind direction is from north-east. This is explained by a topographical deflection of the regional flow in the area caused by the southernmost tip of the Carpathian mountains in the region of Bratislava, north of the site. These wind directions show on average lower wind speeds as they are mainly observed in anti-cyclonic conditions.

Besides wind data, dispersion models need parameters describing the vertical structure of the boundary layer (the atmospheric stability) as input. This information can be provided in its simplest form by discrete stability classes or by more sophisticated direct measures of atmospheric turbulence from 3-D sonics. An estimate of atmospheric stability is obtained using the standard deviations of the three wind components and the Obukhov stability parameter (OSP, in $\left.\mathrm{m}^{-1}\right)$. Before 3-D ultrasonic anemometers were commonly available, assumptions of the relationship between the standard deviations of the three wind components and the mean wind speed were used; we followed those proposed by Robins (1979) and given in Table 1. The calculation of the peak-to-mean curves both for standard meteorological data as well as for ultrasonic anemometer data is described in detail in Piringer et al. $(2007,2013)$.

\section{Results and discussion}

The ratios of the standard deviations of the three wind components to the horizontal wind velocity are displayed in Table 1. Besides the values from Robins (1979), which are independent of a specific site, also those derived from ultrasonic anemometer measurements (OSP) are given; the two sets of values differ considerably. At both sites, the ratios derived from ultrasonic anemometer measurements show a strong dependence of $\sigma_{u} / u$ and $\sigma_{v} / u$ on stability and generally larger values than suggested by Robins (1979). The dependence of $\sigma_{w} / u$ on stability is generally in the range provided by Robins (1979), but lower values are mostly found, especially at Kittsee.

The peak-to-mean algorithm used in the AODM calculates large peak-to-mean ratios near the source. The reduction of the peak-to-mean ratio with distance due to turbulent mixing is described by exponential attenuation functions (Mylne and Mason, 1991; Mylne, 1992). The attenuation curves for the two sites are displayed in Fig. 1a-b (solid lines: Robins, 1979; dashed lines: OSP). Generally, all peak-to-mean curves approach the value of 1 after some distance from the source, usually within a few hundred meters or less. In unstable conditions, the use of OSP from sonics gives larger peak-to-mean factors, whereas in neutral and stable conditions, the differences between Robins (1979) and OSP are not as large and not systematic. The Robins' (1979) curves are of course the same in both figures. 

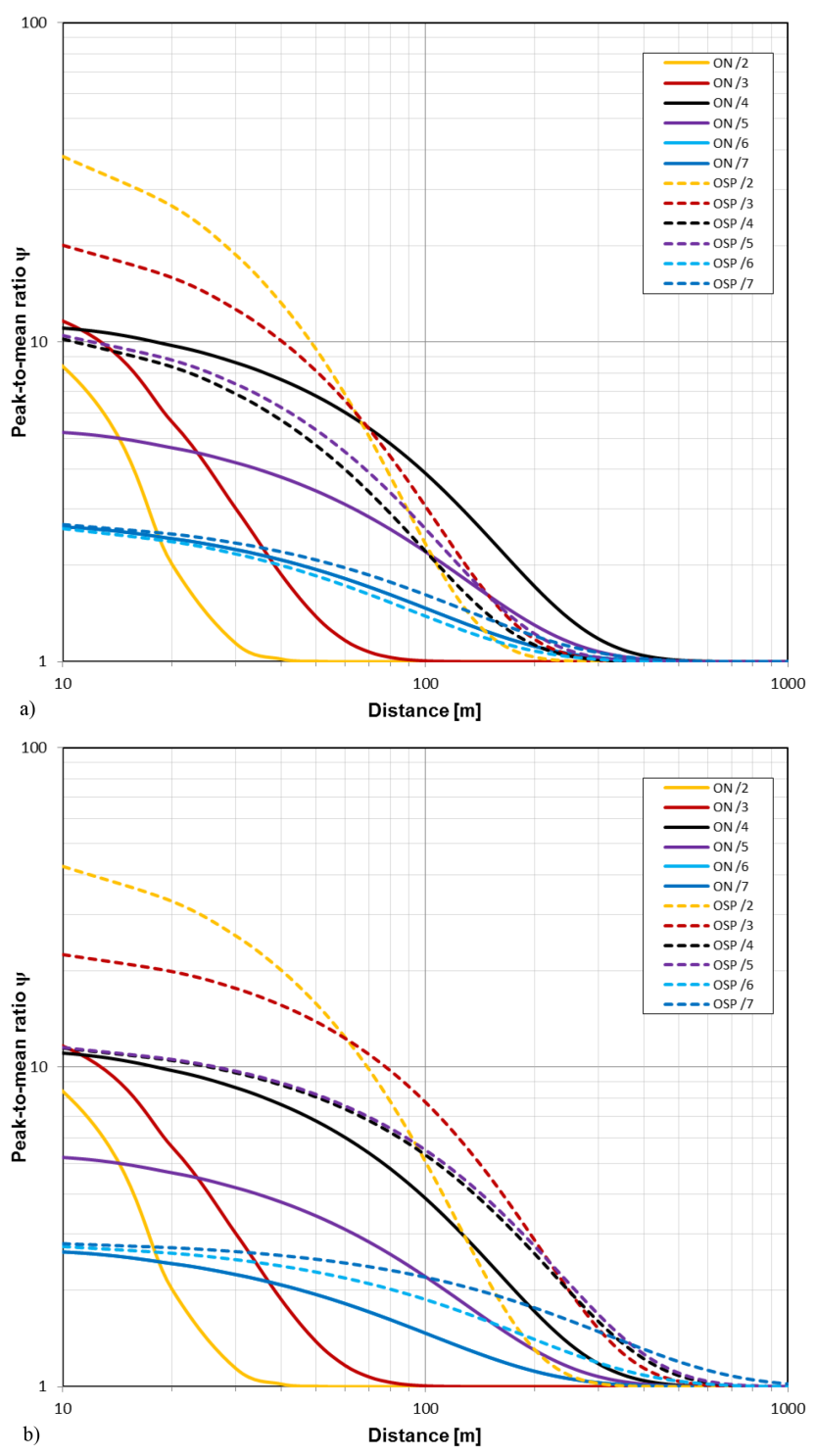

Figure 1. Peak-to-mean ratio attenuation curves dependent on atmospheric stability (classes 2 to 7) for (a) Linz and (b) Kittsee. The solid lines (ON) indicate the curves derived from Robins (1979) and the dashed lines (OSP) indicate those determined using the Obukhov stability parameter from the three-dimensional ultrasonic anemometer.

There are sometimes remarkable differences in the peakto-mean curves between the two sites. The peak-to-mean ratios for unstable conditions (classes 2 and 3) using OSP are much greater near the source compared to the curves from Robins (1979), and their decrease with distance seems to be reduced, leading to peak-to-mean ratios at $100 \mathrm{~m}$ between about 2.5 and almost 10 (see Fig. 1). According to Robins (1979), a peak-to-mean ratio of only 1 is obtained at $100 \mathrm{~m}$ in unstable conditions. At Kittsee, the attenuation curve for class 3 indicates values above 1 several $100 \mathrm{~m}$ downwind. For neutral and stable conditions, the differences

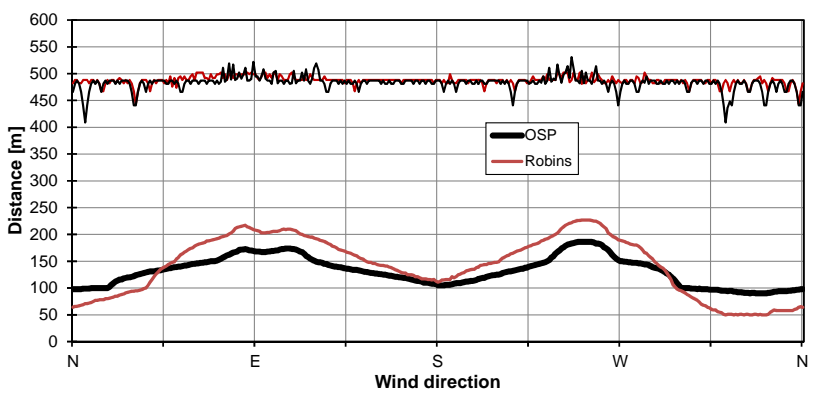

a)

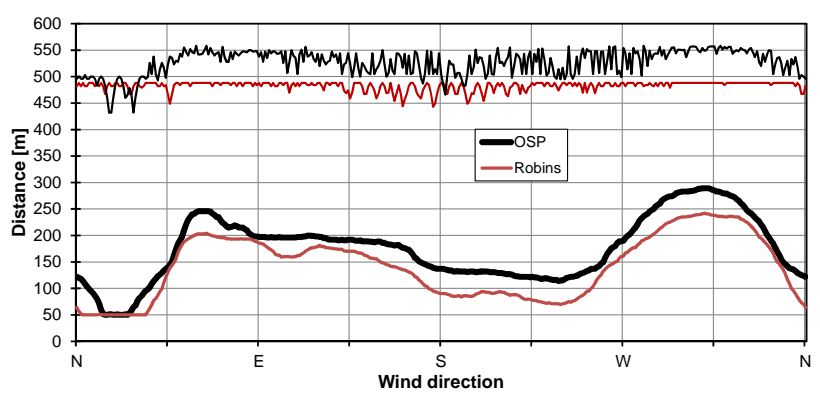

b)

Figure 2. Separation distances for (a) Linz and (b) Kittsee. For details, see text.

Table 2. Source data for dispersion calculations with AODM.

\begin{tabular}{lll}
\hline Stack height & {$[\mathrm{m}]$} & 8.0 \\
Stack diameter & {$[\mathrm{m}]$} & 2.7 \\
Exit velocity & {$\left[\mathrm{m} \mathrm{s}^{-1}\right]$} & 3.0 \\
Volume flow & {$\left[\mathrm{m}^{3} \mathrm{~h}^{-1}\right]$} & 60000 \\
Temperature & {$\left[{ }^{\circ} \mathrm{C}\right]$} & 20 \\
Source strength & {$\left[\mathrm{OU}_{E} \mathrm{~s}^{-1}\right]$} & 5200 \\
\hline
\end{tabular}

between the curves are far less pronounced. The peak-tomean ratios decrease less using OSP at Kittsee and more rapidly at Linz.

For odour protection, separation distances to protect the neighbours from odour nuisance can be defined by the socalled odour impact criteria, a combination of odour concentration (mostly a lower threshold of $1 \mathrm{OU}$ (odour unit) per $\mathrm{m}^{3}$ ) and a selected exceedence probability according to a land use category. The separation distances depending on wind direction are shown in Fig. 2. For each wind direction, a cumulative frequency distribution of separation distances is obtained (Piringer and Schauberger, 1999). The upper curves show the maximum separation distances (i.e. the separation distance for the 100 percentile per wind direction), the lower curves those for an exceedence probability of $3 \%$ (or the 97 percentile) for $1 \mathrm{OU} \mathrm{m}^{-3}$. For the two sites, the same source data are used (see Table 2).

At Linz, the maximum separation distances are mostly slightly below $500 \mathrm{~m}$ (see Fig. 2a), irrespective of the method used. This can be explained by the fact that the peak-to-mean 
ratio at this distance is one (see Fig. 1a). At Kittsee (see Fig. 2b), the maximum separation distances of more than $500 \mathrm{~m}$ are larger when determined by OSP, because at this distance peak-to-mean factors can be larger than 1 for OSP only. For practical applications, separation distances for the odour impact criteria, i.e. a combination of the odour threshold and a prescribed exceedence probability (here $3 \%$, equal to the 97 percentile), are more important than the maximum distances. The former are displayed in Fig. 2 as thick lines. As wind direction in meteorology is defined as a wind coming from a certain direction, the separation distance e.g. for East wind is stretching to the West of a source. The use of the 97 percentile leads to a considerable cut-off in each wind direction so that the maximum separation distances of about $500 \mathrm{~m}$ reduce to approximately 200 to $300 \mathrm{~m}$, depending on the meteorological conditions on site. The largest separation distances are calculated for the main wind direction sectors. It is worth noting that this is also a result of the larger abundance of data in these sectors.

At Linz, the Robins' (1979) based site-independent attenuation curves display very often the largest separation distances, especially for the main wind directions. This is caused by the lower site-specific peak-to-mean factors at larger distances in neutral and stable conditions, compared to those derived from OSP (see Fig. 1a). However, the peak-tomean factors in Kittsee are higher at larger distances than obtained from the standard procedure, causing the larger OSPderived separation distances there.

For the meteorological interpretation of separation distances, peak-to-mean factors for large distances (at least $100 \mathrm{~m}$ ) are most relevant. At shorter distances the implicit assumption in Gaussian plume models that the longitudinal diffusion is negligible compared to the lateral and vertical diffusion is no longer valid. At Linz, peak-to-mean factors beyond $100 \mathrm{~m}$ distance are about 3 at most and decrease rapidly to 1 with distance, irrespective of the method with which they are determined (see Fig. 1a). Hence, the influence of specific stability conditions on the separation distances should be small. The largest separation distances of up to $230 \mathrm{~m}$ are calculated for westerly wind (see Fig. 2a), which shows the highest frequency of large wind speeds. Only for the seldom occurring northerly wind, separation distances with Robins' (1979) approach are smaller than those obtained with the OSP method. This can be explained by the fact that this wind direction sector, in contrast to all others, is associated with low wind speeds and a high frequency of unstable dispersion categories. The latter are, however, relevant for larger separation distances in the OSP-derived approach with higher peak-to-mean ratios in unstable conditions (see Fig. 1a) compared to those from Robins (1979) with peak-tomean ratios of about 1 beyond $100 \mathrm{~m}$ in unstable conditions.

At Kittsee (see Fig. 2b), the largest separation distances of 250 to $300 \mathrm{~m}$ are calculated for the wind directions with on average highest wind speeds (in this case wind from northwest). As the peak-to-mean factors determined from OSP for this site (see Fig. 1b) are larger than the site-independent values from Robins (1979), the site-specific separation distances are larger by about $50 \mathrm{~m}$ for almost all wind direction sectors.

\section{Concluding remarks}

The comparison of separation distances derived with the site-independent Robins' (1979) approach and site-specific ultrasonic anemometer data has been undertaken for two sites in Austria in flat terrain without nearby obstacles. For neighbourhood protection it is important to use a method that will predict the likely largest separation distances. The results suggest that in low wind speed/elevated turbulence conditions, such as in Linz, the Robins' (1979) peak-tomean factors tend to provide the largest separation distances (see Fig. 2a). In high wind speed/low turbulence conditions, such as in Kittsee, OSP determined from 3-D ultrasonic anemometers results in larger separation distances (see Fig. 2b). These results are preliminary, but more ultrasonic data will likely be available in the future to support or deny this hypothesis.

The use of site-specific attenuation curves will increase the reliability of dispersion calculations used for regulatory purposes (e.g. when licensing livestock farms) particularly under unstable conditions. This approach is recommended whenever applicable.

Acknowledgements. This research was funded by the Austrian ministry of Science and Research.

Edited by: C. Chemel

Reviewed by: I. Mavroidis and another anonymous referee

\section{References}

Baechlin, W., Ruehling, A., and Lohmeyer, A.: Bereitstellung von Validierungsdaten für Geruchsausbreitungsmodelle - Naturmessungen (A validation data set for odour dispersion models - field measurements), Forschungsbericht FZKA-BWPLUS, Förderkennzeichen BWE 20003, Ingenieurbüro Lohmeyer, Karlsruhe, Dresden, 183 pp., 2002.

Best, P., Lunney, K., and Killip, C.: Statistical elements of predicting the impact of a variety of odour sources, Water Sci. Technol., 44, 157-164, 2001.

Kleemann, A. M., Kopietz, R., Albrecht, J., Schöpf, V., Pollatos, O., Schreder, T., May, J., Linn, J., Brückmann, H., and Wiesmann, M.: Investigation of breathing parameters during odor perception and olfactory imager, Chem. Senses, 34, 1-9, 2009.

Mylne, K. R.: Concentration fluctuation measurements in a plume dispersing in a stable surface layer, Bound.-Layer Meteorol., 60, 15-48, 1992.

Mylne, K. R. and Mason, P. J.: Concentration fluctuation measurements in a dispersing plume at a range of up to $1000 \mathrm{~m}, \mathrm{Q}$. J. Roy. Meteorol. Soc., 117, 177-206, 1991.

Piringer, M. and Baumann-Stanzer, K.: Selected results of a model validation exercise, Adv. Sci. Res., 3, 13-16, 2009. 
Piringer, M. and Schauberger, G.: Comparison of a Gaussian diffusion model with guidelines for calculating the separation distance between livestock farming and residential areas to avoid odour annoyance, Atmos. Environ., 33, 2219-2228, 1999.

Piringer, M. and Schauberger, G.: Dispersion modeling for odour exposure assessment, in: Odour Impact Assessment Handbook, edited by: Belgiorno, V., Naddeo, V. and Zarra, T., Wiley, Chichester, West Sussex, UK, 125-176, 2013.

Piringer, M., Petz, E., Groehn, I., and Schauberger, G.: A sensitivity study of separation distances calculated with the Austrian Odour Dispersion Model (AODM), Atmos. Environ., 41, 1725-1735, 2007.

Piringer, M., Petz, E., Groehn, I., and Schauberger, G.: Corrigendum to "A sensitivity study of separation distances calculated with the Austrian Odour Dispersion Model (AODM)" [Atmos. Environ. 41 (2007) 1725-1735], Atmos. Environ., 67, 461-462, 2013.
Reuter, H.: Die Ausbreitungsbedingungen von Luftverunreinigungen in Abhängigkeit von meteorologischen Parametern (Dispersion conditions of airborne pollutants in dependence on meteorological parameters), Archiv für Meteorologie, Geophys. Bioklimatol. A, 19, 173-186, 1970.

Robins, A. G.: Development and structure of neutrally simulated boundary layers, J. Indust. Aerodyn., 4, 71-100, 1979.

Schauberger, G., Piringer, M., and Petz, E.: Diurnal and annual variation of the sensation distance of odour emitted by livestock buildings calculated by the Austrian odour dispersion model (AODM), Atmos. Environ., 34, 4839-4851, 2000.

Schauberger, G., Piringer, M., Schmitzer, R., Kamp, M., Sowa, A., Koch, R., Eckhof, W., Grimm, E., Kypke, J., and Hartung, E.: Concept to assess the human perception of odour by estimating short-time peak concentrations from one-hour mean values, Reply to a comment by Janicke et al., Atmos. Environ., 54, 624628, 2012. 